\title{
La violación del domicilio en el Código Penal Peruano
}

\author{
Por Alcjandro Román Rizarola \\ (Alumno del $2^{\circ}$ año de Derecho)
}

Las garantias constitucionales, conjunto de declaraciones contenidas en la Constitución, tienen por objeto proteger la libertad individual, asegurar la vida y los derechos de los ciudadanos, constituyendo la condición primordial de toda democracia. Estas garantías según nuestra Carta Fundamental, pueden ser nacionales, si se refieren a los ingresos y egresos de la Nación, al sistema monetario, al trabajo, a la propiedad: sociales, las que establecen la igualdad de todos los hombres ante la ley, la libertad de comercio e industria; e individuales, si se refieren a la libertad individual en sus distintas manifestaciones, como libertad de conciencia y de creencia, libertad de reunión, libertad de prensa, inviolabilidad del secreto de la correspondencia, inviolabilidad del clomicilio, ete.

Observamos que la Constitución impone, entre otros, la inviolabiliclad del domicilio de to cual se desprende que el que atenta contra dicha clisposición incurre en el delito de violación cle domicilio.

Nuestru Código Penal se ocupa del delito anteriormente mencionado en los Arts. 230 y siguientes, Título III de la Sección V, referente a los delitos contra la libertad, manifestando que comete ziolación de domicilio, el que sin derecho penetrase en moracla o casa de negocio ajena, en sus dependencias o en el recinto habitado por otro, o el que se quedare allí sin hacer caso de la intimidación que le hiciere el que tiene derecho a excluírlo.

CONCEPTO.--Para entender claramente esta figura es preciso tener una noción de lo que se entiende por domicilio. La idea más simple es la que identifica domicilio con habitación, estableciendo que el domicilio es el lugar de la morada de alguien. Este concepto dada 
la complejidad actual de las actividades individuales, ha sido superado, considerándose, hoy, como domicilio no sólo la habitación sino también la casa de negocios; por eso con más propiedad lo definiremos, como el lugar que sirve de manera permanente o transitoria al desenvolvimiento de la vida privada de una persona, de su familia o doncle tiene establecido el centro de sus negocios.

CLASES.-El Código Penal señala distintas clases de domicilios susceptibles de violación:

1.-La morada de una persona o de una familia, entendiéndose. por tal, el local donde uno tiene estaflecido su hogar, temporal o permanente, sea cualquiera su naturaleza objetiva.

2.-La casa de negocio ajona, que puede ser cualquier local en el que se practica una actividad lícita aunque no sea de carácter estrictamente comercial; vg: una oficina, una tienda, etc.

Se considera por regla general que cuando la casa de negocio está abierta al público, vg: cafés, chinganas, etc., no existe el delito de violación en ningún caso. Pero cuando se cierra y sólo quedan clentro el dueño, sus encargados, etc., queda sometido al mismo amparo de la casa habitación. Debemos sin embargo no confundir entre lugares públicos y lugares abiertos al público, ya que estos últimos son en todos los casos lugares privados; vg.: el bufete de un abogado.

3.-Las dependencias de dichas moradas o de las casas de negocios, que es todo aquello que complementa una casa y en donde generalmente viven personas o se guardan cosas; vg: un cuarto separado, un depósito.

4.-Un recinto habitado, o sea cualquier lugar ocupado por una o más personas que por su aspecto externo e interno no puede ser considerado como una casa en el sentido estricto de la palabra: De lo dicho se deduce que no es el local el que determina el concepto de habitación, sino que somos nosotros los que damos por el hecho de vivir en tal o en cual lugar el concepto jurídico de habitación.

SUJETO ACTIVO.- Sujeto activo de este delito puede ser cualquiera persona.

SUJETO PASIVO.-Será sujeto pasiro aquel que teniendo derecho a impedir el acceso a su domicilio resulta atacado por el ingreso arbitrario.

ELEMENTOS.-Debemos distinguir dos clases de elementos: materiales y sicológico:

1.-Constituye la materialización del delito el entrar o permanecer en algunos de los lugares anteriomente expresados contra el consentimiento del que tenga derecho a excluir. 
Entrar, significa pasar de afuera adentro, ya sea por la puerta, por la rentana o por cualquier otro lugar. El ingreso se realiza desde el momento en que el agente pone pie en el lugar constitutivo clel domicilio ajeno. No hay introducción si uno se asoma por la rentana, pues con ello no se perturba el normal desarrollo de las actividades domiciliarias que es lo que la ley trata de garantizar for medio de su tutela.

¿Constituye violación de domicilio chando se llega a la azotea de una casa Sespecto a este punto hay discrepancias. Los tratadistas se han dividide en dos grupos: mos que consideran que no existe delito, va que este refule el hecho material de la peretracion al intering $y$ otros (que dicen que si bo hay. Sobre of particular me parece num acer-

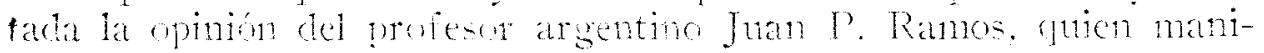
Fiesta que anngue la azotéa no sea comparable per sur funciones at

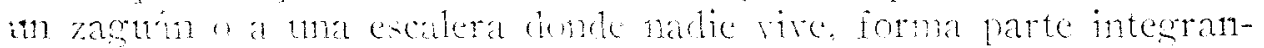

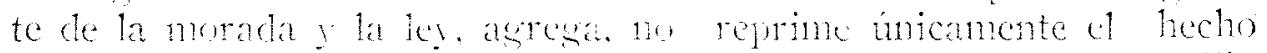

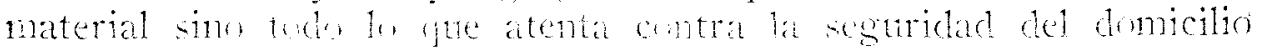

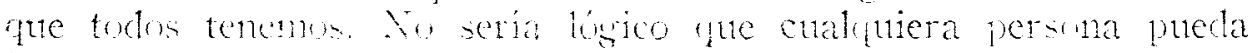

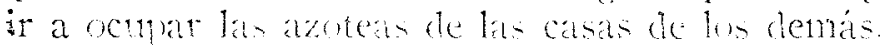

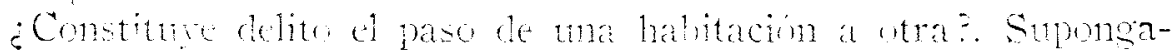

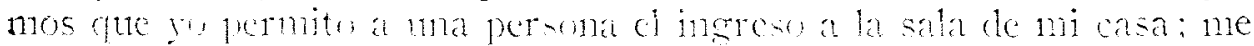
retiro de la habiacion y $\mathrm{n}$ ni ansenca csta porona penetra en la habitación contigua. Evidentemente fue se comete delite, it he pro-

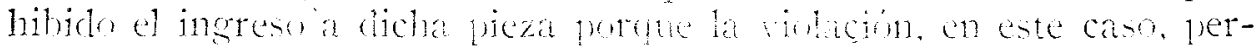
turba la libertar y la trampulictar domentica que la ley protege.

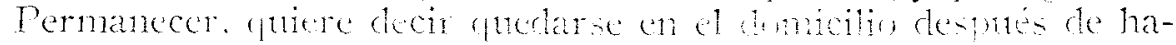

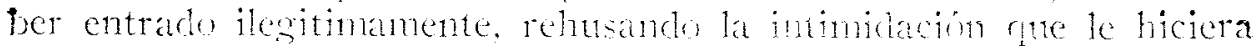

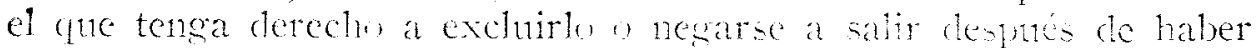
entrado licitamente: ry: un venderter fue se njegne at dejar la casa.

2.-La intromisión o permanencia en lus luesares señadado de-

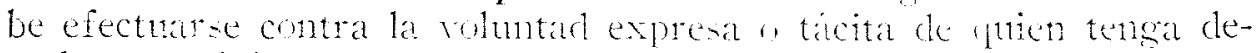
recho a excluir: con engaño o clandestinanente.

Tiene derecho a exchuir el jefe de la fanilia o en su anencia sus faniliares. Este derecho de exclusión pucde ser ejercido contra el mismo propietario de la finca por el locatario.

Cuando la roluntad es expresa y realizada por alguna de las personas referidas no hay ninguna ducla. Pero no sucede to mismo cuando surge lo que se llama la voluntad presunta. Así. por ejemplo, si ingresa una persona a una casa para realizar actos inmerales con alguno de sus ocupantes, es obvio que la roluntad del dueño de la casa es prestunta, no sienclo necesaria la notificación previa. No es indispensable en caso de introducción engañosa o clandestina, prohibición expresa, pues. se presupone. 
3.-La introducción o permanencia ha de ser ilegítima. Por eso establece el Código en el Art. 231, que el que entrase en morada ajena para evitar un mal grave, a si mismo, a los moradores o a un tercero para cumplir un deber de humanidad o para prestar auxilio a la justicia no comete delito de violación de domicilio.

4.- - Respecto al elemento sicológico de este clelito los tratadistas difieren. Se observan dos corrientes: una que exige como requisito para que se produzca el clelito de violación de domicilio, la intención de violarlo, y la otra que considera que basta el hecho de la riovación no inportando la intención.

Tistino rine, tanto en el primer como en el segundo caso, se debe considerar cono violado el domicilio, si se penetra en él sin atitorización. ya que si se exigiera la prueba de la intención delictuosa serviría dn muchos casos de escapatoria y justificaría verdaderos delitus cie viacion. Eso si, si fuera claro que el moril era inocente, como en el caso de que una persona entrase en una casa ajena en persecución de otra ane le ha faltado en plena calle y que viviese allí, se podría atenuar la pena considerándolo sólo cono un delito culposo. Di(yo cnlpos por concurrir los elementos que lo caracterizan para si incriminacion: violación del ordenamiento jurídico y rohntad; roluntad para dejar de hacer lo que debió haberse hecho, tal era el reparar en que no se debe entrar en domicilio ajeno.

Este delito adnite la tentativa, tal sería el caso de una persona a cuien se encuentre tratando de derribar la puerta de mua casa para entrar a ella.

PENA.-La pena será de prisión no mayor de dos años o multa cle la renta de tres a treinta días. (art. 230 del C. P.).

ACCION PENAL.-La acción penal se ejerce sólo por denuncia del agraviado.

WIOLACION DEL DOMICILIO COMETIDO POR FUNCIONARIO PUBLICO.-Nuestro Código se ocupa de ello en la segunda parte del Art. 230, estableciendo qute se impondrá, además de la pena de prisión no mayor de dos años o de la multa de la renta de 3 a 30 días, la inhabilitación especial de seis meses a dos años al funcionario público o agente de la autoridad que allanare un domicilio sin las formalidades prescritas por la ley o fuera de los casos que ella determina.

La Constitución exige para el allanamiento del domicilio el mandato escrito y motivado del Juez o de la autoridad competente, el que deberá mostrarse previamente al dueño de la casa a la que se va a penetrar. 